

Revista Mexicana de Derecho Constitucional Núm. 41, julio-diciembre 2019

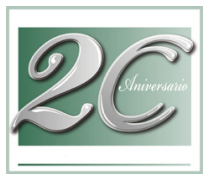

\title{
Estado constitucional y fragmentación social: la aporía del siglo XXI
}

\author{
Constitutional state and social fragmentation: the aporia \\ of the 21st century
}

\section{Enrique URIBE ARZATE*}

RESUMEN: La crisis que actualmente vive el Estado es evidente en los enormes retos que enfrenta dentro y fuera de sus fronteras; dentro, es incapaz de atender necesidades básicas de los habitantes; fuera, los poderes metaestatales anulan su capacidad de decisión. Ante la grave crisis que enfrenta el Estado de derecho o Estado legislativo, el cambio de paradigma hacia el Estado constitucional implica que la organización política debe ser capaz de garantizar los derechos de los habitantes y de poner freno al abuso del poder público. El actual escenario que viven las sociedades nos muestra una aporía insalvable: el Estado cuenta con el mayor desarrollo teórico; empero, en la realidad es evidente su incapacidad para garantizar la seguridad y la justicia para los habitantes. Así, el Estado fracturado, o fallido, como también se le ha llamado, hace inviable el bienestar y cualquier otra aspiración elemental de los habitantes.

Palabras clave: Estado constitucional, derechos humanos, control del poder.
ABSTRACT: The current crisis of the State is evident in the enormous challenges it faces inside and outside its borders; within is unable to provide the basic needs of the inhabitants; outside, the international organizations and its powers, nullify their capability of decision. In spite of the serious crisis faced by the Rule of Law or Legislative State, the change of paradigm towards the "Constitutional State", implies that the political organization must be capable of guaranteeing the rights of the inhabitants and put efficient limits to the abuse of public power. The status quo of societies, shows an insurmountable aporia: The State has the greatest theoretical development; however, in the today's life, its inability to guarantee security and justice for the inhabitants is evident. Thus, the Fractured State, or Failed State as it has also been called, makes the welfare and any other elementary aspiration of the inhabitants unviable.

Keywords: Constitutional state, human rights, constitutional control.

* Profesor de tiempo completo en la Universidad Autónoma del Estado de México. Doctor en derecho por la UNAM, México; vercingtx@hotmail.com. 
SUMARIO: I. Introducción. II. El estado de la cuestión. III. Seguridad humana y justicia social. IV. Policía para la polis. V. La democracia vivencial. VI. Próximas tareas. VII. Fuentes de consulta.

\section{INTRODUCCIÓN}

El mundo vive una época de crisis que se manifiesta de múltiples maneras en lo político, social, económico, institucional, cultural, y en otras proyecciones más preocupantes aún, como en la carencia de valores para la convivencia humana en civilidad. Esta crisis tiene varios enfoques para su análisis adecuado: por un lado, una visión global que nos permite mirar qué pasa más allá del Estado y, por otra parte, una perspectiva de orden local que hace posible advertir de manera cercana e inmediata qué sucede con el Estado y su gobierno, y cómo se estructura la relación entre estos dos y los habitantes. A fin de cuentas, la complejidad que todo esto entraña es una crisis del poder público que se traduce también en una crisis de legitimidad que cuestiona sin distingo de partidos políticos, ideologías, colores o credos, a cualquier gobierno que ejerza poder sobre los seres humanos.

De este modo, podemos decir que el Estado está en crisis, y que las actuales tensiones que enfrentan las sociedades son resumen de dos grandes tendencias, a saber: los ejercicios enfocados a demostrar la capacidad de decisión local (para algunos expresión irrefutable de la soberanía) y, por otro lado, el afianzamiento de reglas de operación de los poderes metaestatales, diseñados y operados desde fuera de la potestad del Estado. ${ }^{1}$

Este doble accionar nos ubica de frente a una realidad cotidiana que es, en sí misma, una contradicción y que teóricamente resulta difícil de explicar. ¿Cómo puede seguir siendo el Estado, "la organización normalmente más poderosa dentro de su territorio", ${ }^{2}$ si las expresiones locales, regionales o

1 En cuanto a lo primero, es elocuente el caso de Cataluña, que no ceja en sus intentos por separarse de España (independentistas o secesionistas, según se quiera ver), así como los asomos e intentos en el mismo sentido de Quebec en Canadá, y Escocia en el Reino Unido. En cuanto a lo segundo, no requiere mayor referencia el poder del Fondo Monetario Internacional o del Banco Mundial y su innegable influencia en las decisiones domésticas de los países.

2 Heller, Hermann, Teoría del Estado, México, FCE, 2000, p. 310. 
autonómicas ponen en entredicho su potestad y hasta su legitimidad?, ¿para dónde se puede mover el poder del Estado, si muchas de sus decisiones esenciales son dictadas desde otros espacios? ¿para dónde se puede manifestar la soberanía de los pueblos, si cualquier asomo en este sentido se enfrentará a nuevas reglas que prácticamente la han acotado?

En esta zona nos movemos actualmente los seres humanos. Más allá de nacionalidades e ideologías, lo cierto es que las reglas del mercado y su expresión —ya desde ahora rancia-, que es la globalización, se han encargado de hacernos más iguales y más idénticos en cualquier país y latitud. ${ }^{3}$ Sobre esto, es pertinente acotar lo siguiente: "Globalidad es definida como el hecho de haber estado mucho tiempo viviendo en una sociedad mundial y globalización se refiere al fenómeno por el cual la soberanía del Estado es amenazada por actores transnacionales y está caracterizada por la convergencia de culturas y sociedades". ${ }^{4}$

Pues bien, ¿cómo enfrentar este dilema?, ¿cómo afirmar el sello de lo estatal en medio de esta burda y grosera manera de barrer las identidades y la cultura particular de cada pueblo?, ¿qué opción hay ante el asedio y la imposición de patrones y parámetros idénticos? Aún más, ¿cómo podrán el Estado de derecho, sus poderes y sus instituciones, afirmar su presencia y capacidades jalonados por esta convulsión global? Las respuestas — apenas germinales - deben considerar que la fragilidad de las estructuras locales de cada Estado y las graves circunstancias del contexto internacional nos han situado en una profunda crisis, silente en muchos aspectos, pero abrupta en los indicadores económicos y de bienestar. Por ello, sin ambages podemos afirmar que la pobreza sigue siendo el mayor flagelo para la humanidad, ya no sólo por lo que representa en sí misma, sino además por las severas consecuencias que acarrea. ${ }^{5}$

3 "A estas alturas de la historia lo que predomina es la multitud de trabajadores, poblaciones o colectividades nacionales, dispersas en grupos, etnias, minorías, clases, regiones, culturas, religiones, sectas, lenguas, dialectos, tradiciones culturales, todos como miembros de una extraña aldea global"; Ianni, Octavio, La sociedad global, México, Siglo XXI Editores, 2007, p. 76.

4 Flores, María Victoria, "La globalización como fenómeno político, económico y social”, Orbis. Revista Científica Ciencias Humanas, Venezuela, vol. 12, núm. 34, 2016, pp. 26-41, p. 38, disponible en: http://www.redalyc.org/articulo.oa? $i d=70946593002$ (consultado el 21 de junio de 2018).

5 Aquí se inscribe lo que Held ha mencionado: “Allí donde las relaciones de poder generan asimetrías sistemáticas de perspectivas de vida, se crea una situación que puede ser denominada «nautonómica». La nautonomía se refiere a la producción y distribución 
Ante estas circunstancias, el paradigma del Estado constitucional que se ha ideado como relevo del Estado de derecho consigna el control del poder y la garantía de los derechos humanos, pero lamentablemente el nuevo modelo de organización estatal padece la aporía inocultable entre las prescripciones normativas de más alto nivel y su incapacidad ad intra y ad extra, para imponer su potestad y cumplir cabalmente con sus dos grandes propósitos, ya anotados. Al respecto, no debemos olvidar que "todo Estado moderno occidental se caracteriza a sí mismo como democrático y como sometido a la ley. Ningún Estado puede ignorar o desechar estos términos, pues ellos inciden directamente en la legitimidad de la comunidad política y de su forma de gobierno". ${ }^{6}$ Justamente de aquí deriva la concepción del Estado constitucional, pues se trata entonces de una organización humana políticamente organizada, que cifra su destino en el acatamiento a la ley y, desde luego, a su Constitución. Ahora bien, a diferencia del Estado legal de derecho que identifica al derecho con la ley, el Estado constitucional asienta con claridad que la Constitución es el ordenamiento superior que dicta los grandes lineamientos del quehacer público. De este modo, Constitución y democracia se anudan en una poderosa relación simbiótica que es capaz de afianzar y asegurar los derechos de los gobernados y poner coto al ejercicio del poder público.

De acuerdo con este hilo argumental, el desiderátum normativo de los derechos humanos y del control de poder es el andamiaje irremplazable para la realización de las grandes tareas del Estado constitucional; desde luego, el Estado debe cumplir debidamente con ambos escenarios y, por eso, es inaceptable que el gobierno permanezca inmóvil ante las necesidades y expectativas ciudadanas que exigen acciones para el control del poder y tareas

asimétrica de perspectivas de vida, que limitan y erosionan las posibilidades de participación política"; Held, David, La democracia y el orden global, del Estado moderno al gobierno cosmopolita, Barcelona, Paidós, 1997, p. 210. Nosotros solamente preguntamos: ¿acaso hay algo más reprochable en el statu quo predominante que la cancelación de oportunidades de realización para cualquier persona? Sobre este punto puede verse, Cordera Campos, Rolando y Provencio Durazo, Enrique (coords.), Informe del desarrollo en México 2015, México, UNAM, 2016, donde se da cuenta de la evolución de la pobreza y los riesgos que de ella derivan; en el mismo sentido, Cordera Campos, Rolando (coord.), Percepciones, pobreza, desigualdad. Encuesta nacional de pobreza, México, UNAM, 2015.

6 Kahn, Paul W, "Una nueva perspectiva para el constitucionalismo comparado: el análisis cultural del Estado de derecho occidental", Revista de Derecho, Valdivia, vol. XXIX, núm. 1, junio de 2016, p. 242, disponible en: https://www.redalyc.org/articulo. oa? id $=173746326011$. 
concretas para el respeto de los derechos humanos. La idea de la dignidad humana como premisa cultural antropológica del Estado constitucional ${ }^{7} \mathrm{da}$ cuenta de la enorme importancia que la garantía de los derechos humanos tiene para la mejor concepción del Estado en el momento actual.

En este orden de ideas, el Estado mexicano que se estima como constitucional, democrático, social y de derecho, tiene que ser garante de los derechos de los habitantes - visibles desde la concepción de la seguridad humana-y del control del poder — posible desde la democracia vivencial- Estas dos condiciones inexcusables expresan con reciedumbre la dimensión basal del Estado constitucional; si el Estado mexicano no es capaz de asegurar mínimamente la dignidad humana y de poner freno al abuso de poder, la aporía antes señalada seguirá enquistada en nuestra organización política, normativamente defendible, pero expresiva, sin duda, de una realidad atroz para muchos mexicanos.

\section{EL ESTADO DE LA CUESTIÓN}

El contexto de este ingente desafío es complejo; su mejor comprensión debe incluir problemas metaestatales que atenazan a los Estados e inmovilizan cualquier intento por superar las diversas dimensiones de la crisis. Así, terrorismo, narcotráfico, guerrilla, tortura, contaminación, abuso del poder y corrupción, entre tantas otras miserias, ahogan la res pública y mantienen inermes a los habitantes. Con esto, no tratamos de justificar el fracaso de muchas de las acciones estatales, queremos solamente dar cuenta de la incidencia multifactorial que limita o impide su funcionamiento adecuado. Y es que el Estado y su sociedad (y la sociedad y su Estado) son parte de un todo; pocos o casi ningún fenómeno actual se pueden asumir como asuntos de la incumbencia exclusiva y excluyente de un pueblo en particular. ${ }^{8}$ De los temas citados en vía de ejemplo, ninguno tiene raíces esencialmente locales; su savia circula en el tejido social de cualquier pue-

7 Cfr. Häberle, Peter, El Estado constitucional, México, UNAM, Instituto de Investigaciones Jurídicas, 2003.

8 "Poco a poco, la morfología de la sociedad global involucra a los derechos humanos, narcotráfico, protección del medio ambiente, deuda externa, salud, educación, medios de comunicación de masa, satélites y otros puntos. Asuntos sociales, económicos, políticos y culturales que siempre parecieron nacionales, internos, se vuelven después internacionales, externos, relacionados con la armonía de la sociedad global"; Ianni, op. cit., p. 26. 
blo. Por ejemplo, el narcotráfico, ahora tan señalado como asunto prioritario para México, ${ }^{9}$ es todavía tema de preocupación en Colombia y gran parte de los países de la región centro y sudamericana; en términos similares, países tan distantes geográficamente de los ya citados, como Singapur o Malasia, padecen este problema y sus secuelas. Y sobre el terrorismo, siempre faltarán palabras para expresar lo inhumano y bestial de los traumáticos eventos de Estados Unidos en 2001, España en 2003, París en 2015 y 2016, y Manchester en 2017; lamentablemente habrá más referencias de eventos infaustos como éstos en los años posteriores.

De este modo, podemos constatar que en el mundo actual ya no hay parcelas, y que las fronteras operan (discretamente) como ilusión que separa y (fuertemente) como causa de la discriminación y el oprobio; en la comprobación cotidiana de la justificación y funcionalidad de estas estructuras humanas, de carácter político-ideológico — no pocas veces forzadas-, la globalización en lo económico, guarda correspondencia matemática con la mundialización de los problemas comunes. El hostigamiento y saqueo del patrimonio cultural es un asunto de la humanidad, porque lo mismo sucede en la antigua Mesopotamia que en casi cualquier otro país donde se asentaron las culturas de la antigüedad; la infición es cosa cotidiana en China y en todas las metrópolis; la trata de personas y la delincuencia organizada tampoco tienen fronteras.

Tal estado de cosas ha puesto en jaque a los modelos tradicionales de organización humana: la familia nuclear no resiste el acoso de otros tipos de asociación humana; la política se ha rebajado al improductivo debate entre políticos y las mutuas acusaciones sin sentido; el lucro y la depredación son medio y fin de los dueños del dinero y llevado a una dimensión mayor, son el único propósito del capitalismo y del imperio. ${ }^{10} \mathrm{Y}$ en la vorágine de todo este panorama, la organización jurídico-política más

9 Este asunto es prioritario para México, pero también debe involucrar a otros países. Cabe señalar que apenas el 18 de mayo de 2017, los secretarios de Estado y de seguridad de los Estados Unidos reconocieron que sin demanda no hay oferta, y que el problema del narcotráfico los involucra a ellos como consumidores. Véase http://www.jornada.unam. $m x / 2017 / 05 / 19 /$ politica/004n1pol.

10 En relación con lo último, Chomsky se ha referido a "la quinta libertad". Las cuatro primeras son la libertad de expresión, la libertad de culto, estar libres de necesidades y estar libres de temor. La quinta tiene una expresión terrible, pues se refiere a la "libertad de saquear y explotar". Véase Chomsky, Noam, La quinta libertad, Barcelona, Crítica, 1988, pp. 79 y ss. 
trabajada (el Estado) ensombrece y parece condenada a desaparecer. El Estado vive la peor de sus crisis. ${ }^{11}$

En vista de la doble configuración de esta problemática, que se manifiesta al interior del Estado y más allá de sus fronteras, nosotros solamente nos ocuparemos de la dimensión estatal ad intra, para dejar las cuestiones de orden externo para otro análisis. En este mismo orden de ideas, las referencias tomarán como caso de estudio a México, aun cuando la temática aquí tratada puede abordar a cualquier Estado con similar problemática.

Así las cosas, los problemas de dimensión metaestatal se vuelven - paradójicamente - mayores al seno del Estado. Para frenar a los delincuentes no hay policía capaz ni en la vía preventiva ni en la remedial. Para combatir a quienes contaminan, el obeso aparato estatal de la materia simplemente no sirve; el terrorismo - amenaza en tiempo real, latente y ubicua- es probablemente el único parámetro de igualdad efectiva de nuestra época, porque a nadie discrimina y ninguno está a salvo. El narcotráfico nos tiene en la incertidumbre y la zozobra, y la policía infiltrada de corrupción y complicidades —amén de sus limitaciones - está colapsada. Los programas de combate a la pobreza son temporales y de efecto limitado — dada su improvisación y superficialidad-, cuando no son llevados de la mano por la frivolidad y el uso político que en no pocos lugares canjea dinero, despensas, tarjetas y hasta televisores por votos. ${ }^{12}$

Esta es la fisonomía del Estado de derecho, maltrecho y en crisis. Muchos países son, lamentablemente, ejemplo de este caos. Y por eso, el paradigma de relevo ha sido el Estado constitucional que pretende garantizar los derechos humanos y poner coto al ejercicio del poder público; empero, las crisis y la fragmentación social, visibles en la miseria y la corrupción,

11 "El estado nacional ha dejado de ser lo que fue durante casi dos siglos: el principal organizador de la vida política, económica, social y cultural de los pueblos. Ello se debe a dos procesos dinámicos paralelos: por una parte, la constitución de conjuntos económicos y políticos metanacionales, como la Unión Europea y el proceso de la globalización económica, y por la otra, el resurgimiento de actores sub-estatales o a veces trans-estatales de tipo regional o etnonacional que desafían a los conceptos clásicos asociados al Estado nacional"; Stavenhagen, Rodolfo, "Un mundo en el que caben muchos mundos: el reto de la globalización”, en Gutiérrez Martínez, Daniel y Balslev Clausen, Helene (coords.), Revisitar la etnicidad, miradas cruzadas en torno a la diversidad, México, El Colegio de Sonora-El Colegio Mexiquense-Siglo XXI Editores, 2008, p. 384.

12 La insania que acompaña a las campañas electorales en México es un ejemplo quizá insuperable. 
han limitado en la práctica la consecución de los dos grandes objetivos del Estado constitucional. Como dice Aragón:

\begin{abstract}
Quizá un modo de evitar esos riesgos y conjurar ese peligro sea del de "constitucionalizar" nuevamente el "constitucionalismo", y no es un juego de palabras. De lo que se trata es de llevar a la conciencia política y jurídica de nuestros días la convicción de que sólo entendiendo el constitucionalismo como una realidad que ha de conquistarse a diario... pueden mantenerse duraderamente los principios. ${ }^{13}$
\end{abstract}

Pero, ¿por qué el paradigma del Estado constitucional no ha podido materializar sus dos grandes propósitos?, ¿qué hace falta para concretar su quid y telos? Como podemos ver, la aporía anunciada en el acápite es notoria en la incapacidad del Estado constitucional que no acaba de consolidar en la praxis el control del poder y la garantía de los derechos humanos; la miseria es tanta y la corrupción tan grande, que el Estado-tipo - ideado y centrado en la constitucionalidad- corre el enorme riesgo de no contar con los argumentos y la capacidad para revertir las condiciones tan desfavorables que hacen nugatorio cualquier derecho fundamental.

En medio de este escenario, no cabe duda que de todos los asuntos prioritarios y complejos, los seres humanos enfatizan la demanda de seguridad y justicia. En estos campos, el ejercicio de la potestas tiene muchas asignaturas pendientes con los habitantes. Sólo en vía de ejemplo, podemos decir que en el caso mexicano, la seguridad pública perdió la brújula desde la poco mesurada decisión de enviar al ejército a las calles a cumplir "inconstitucionalmente"14 con una tarea que no es aquiescente con la formación de los militares; las consecuencias de esto son los miles de muertos

13 Aragón Reyes, Manuel, "Dos problemas falsos y uno verdadero: «neoconstitucionalismo», "garantismo» y aplicación judicial de la Constitución”, Cuestiones Constitucionales, Revista Mexicana de Derecho Constitucional, México, núm. 29, julio-diciembre de 2013, p. 19.

14 Dice el artículo 21 de la Constitución Política de los Estados Unidos Mexicanos: “...Las instituciones de seguridad pública serán de carácter civil, disciplinado y profesional. El Ministerio Público y las instituciones policiales de los tres órdenes de gobierno deberán coordinarse entre sí para cumplir los objetivos de la seguridad pública y conformarán el Sistema Nacional de Seguridad Pública, que estará sujeto a las siguientes bases mínimas...”. En nuestra opinión, solamente una interpretación muy forzada, que intenta ser sistemática, puede dar matices constitucionales a una atribución que la carta magna no le reconoce expresa y claramente al ejército. 
que nada tienen que ver con el narcotráfico y la brutalidad de los soldados en retenes y emboscadas. ${ }^{15}$ En el otro aspecto, la justicia, particularmente la de los reclamos de ofendidos y víctimas, no ha podido dar respuesta a los asuntos vinculados con delitos de competencia local y menos aún a las graves conductas de la delincuencia organizada.

El calificativo de Estado fallido que se endilgó a México difícilmente se puede atenuar con resultados tan pobres en justicia y seguridad y ante la ausencia de políticas públicas ${ }^{16}$ que entiendan y atiendan estas cuestiones con un enfoque distinto a la confrontación y la guerra. Pero desafortunadamente no es sólo el caso mexicano; la misma fragilidad se advierte en el Estado de derecho ${ }^{17}$ que sirvió de modelo a los países de Latinoamérica, o en el Estado-tipo que sigue vigente en Europa, y ni qué decir de los países de los continentes asiático o africano; los primeros, todavía en una dura batalla por la conquista de derechos esenciales, y los otros, en la eterna lucha contra la miseria y la hambruna.

\section{SEGURIDAD HUMANA Y JUSTICIA SOCIAL}

Con lo antes señalado queda claro que el paradigma de Estado constitucional, hoy aceptado para enfrentar estos flagelos, no ha podido atenuar las penurias de los habitantes, ni cumplir con la más elemental de sus tareas, que es garantizar un mínimo de derechos de los habitantes; tampoco ha podido hacer mella en la corrupción que corroe el tejido social; y ante todo esto, el apremio por hacer que sus postulados tengan una dimensión vivencial y pragmática, se acentúa en la misma medida que los problemas cotidianos - particularmente la injusticia y la inseguridad - atenazan y vulneran a los ciudadanos. Queda claro que la ruta a seguir en la concep-

15 Más allá de los resultados de las investigaciones ministeriales y judiciales, el evento acaecido en Puebla, México (3 de mayo de 2017), que fue registrado en un video, muestra el momento en que un militar — todo lo parece indicar - dispara y mata a una persona que ya estaba sometida. Véase http://www.jornada.unam.mx/2017/05/11/ politica/003n1pol.

16 Una aproximación al contenido y alcances de las políticas públicas, se puede ver en Aguilar Villanueva, Luis F., El estudio de las políticas públicas, México, Miguel Ángel Porrúa, 2007, y en otra obra del mismo autor intitulada La implementación de las políticas públicas, México, Miguel Ángel Porrúa, 2007.

17 Véase, Valadés, Diego, Problemas constitucionales del Estado de derecho, Buenos Aires, Astrea, 2004. 
ción ortodoxa de la seguridad pública acabó mostrando a un Estado represor (dicho técnicamente: a un gobierno represor; dicho eufemísticamente: a un gobierno incapaz y desorientado) que ni con el ejército pudo controlar las expresiones cada vez más cruentas de los cárteles de la droga. Los enfrentamientos entre éstos y las complicidades con integrantes del aparato gubernamental dieron cuenta muy pronto del error garrafal que significó la presencia del ejército en las calles.

En el otro campo, la justicia es una tarea — ahora sí imposible - para cualquier procuraduría o tribunal local o federal. Junto a los asuntos de mayor difusión, como Tlatlaya o Ayotzinapa, que nos han situado en la vergüenza ante el mundo, ninguna procuraduría ha podido (y ningún juzgador podrá) dar respuesta contundente y clara a los deudos de los muertos. Las desapariciones forzadas, la tortura, los escapes de la cárcel — poco menos que surrealistas - de delincuentes de altísima peligrosidad, evidencian una justicia ausente en un Estado que cada día se resquebraja un poco más. En este escenario, la justicia cotidiana que claman los ciudadanos de a pie resulta tortuosa, y es poco menos que una hazaña obtener de los tribunales una aplicación pronta y expedita ${ }^{18}$ en este campo. Con todo y las reformas constitucionales de los últimos años, la justicia sigue siendo tema de preocupación para los habitantes.

Para cerrar el círculo de todos estos agravios, los índices de corrupción en general, y especialmente en los dos temas prioritarios (seguridad y justicia) ya apuntados, son una alerta para el Estado mexicano, situado en este rubro como uno de los países con mayor corrupción en el mundo. ${ }^{19}$

Por todo lo antes referido, la construcción de políticas públicas en los campos más apremiantes — como son la seguridad y la justicia — significa para el Estado constitucional el reto más acuciante en lo inmediato, y va de la mano con la necesidad de hacer una proyección para los próximos

18 Así lo mandata el artículo 17 de la Constitución Política de los Estados Unidos Mexicanos que establece: “...Toda persona tiene derecho a que se le administre justicia por tribunales que estarán expeditos para impartirla en los plazos y términos que fijen las leyes, emitiendo sus resoluciones de manera pronta, completa e imparcial. Su servicio será gratuito, quedando, en consecuencia, prohibidas las costas judiciales...".

19 "Ciudad de México, 27 de enero de 2016 - México se mantuvo sin cambios en el Índice de Percepción de la Corrupción 2015, publicado el día de hoy por Transparencia Internacional y Transparencia Mexicana. El país obtuvo una puntuación de 35 en una escala que va de cero (altos niveles de corrupción) a 100 (bajos niveles de corrupción); esta es la misma puntuación que México obtuvo en la edición anterior", disponible en: http:// www.tm.org. $m x /$ ipc2015/ (consultado el 27 de enero de 2016). 
lustros, pues ni estos asuntos ni el combate a la pobreza podrán afrontarse con éxito en el corto plazo, máxime cuando los mercados internacionales y la inestabilidad de la economía global alcanzan con sus repercusiones cualquier economía local y, por ende, cualquier política pública doméstica.

A partir de un diagnóstico tan poco halagüeño, donde las políticas públicas como acción del Estado no se han desarrollado adecuadamente en los planos preventivo y correctivo, la visión limitada y fragmentada de las cuestiones anudadas a la seguridad y la justicia necesitan un abordaje científico inmediato que permita la superación de categorías desgastadas, como la idea de seguridad "pública" y todos los demás calificativos que a lo largo de los últimos años se le han adherido, o como la vieja concepción de la justicia penal estancada en el propósito de poner tras las rejas al mayor número de delincuentes, sin volver la mirada a las víctimas y ofendidos que en ciertos delitos — como la desaparición forzada y la tortura — son ahora los olvidados del derecho penal.

Así las cosas, la debacle del Estado de derecho, incapaz de prodigar seguridad y justicia, aunada a la evidencia del limitado funcionamiento en otros rubros, nos ha llevado a la exigencia de formular una aproximación científica diferente que, en nuestra concepción, no puede ser otra que la construcción del Estado constitucional de recia orientación social; sin embargo, este tipo de Estado no acaba de consolidar sus preceptos y reglas, ni el nuevo diseño institucional que sea capaz de aportar los elementos esenciales para que los dos tópicos de mayor urgencia que hemos venido citando sirvan de punto de partida en esta demanda colectiva por que la situación de los habitantes cambie pronto.

Dejemos de lado las reformas estructurales (en materia de migración, energía, régimen político-electoral, trabajo, telecomunicaciones, etcétera), las reformas constitucionales e institucionales, la crisis económica, la pobreza y el desempleo; el mayor desaliento y el hartazgo provienen de la inseguridad y la injusticia, mientras el Estado mexicano no sea capaz de modificar esto, ninguna reforma en éstos y en cualquier otro campo tendrá éxito.

Es claro entonces que un asunto de tal envergadura no puede abordarse a partir de las concepciones tradicionales generadas en estos temas. Por ello, creemos que es necesario establecer una postura teórica desde la reconstrucción conceptual que se desprende de la idea de lo público, pasando por la seguridad ciudadana, la seguridad nacional y hasta la seguridad alimentaria que sirven de antecedente teórico a un nuevo enfoque científico, asentado en la idea de la seguridad humana — condición sine 
qua non para la vida humana-. Con esta preocupación central, advertimos que la seguridad humana tiene varios umbrales ya definidos por la ONU, ${ }^{20}$ en los que cada aspecto resulta esencial para atender un desarrollo humano adecuado, al margen del número de policías y armamento con que cuente el Estado. El salto teórico que ha implicado referirnos a la seguridad humana nos ha permitido comprender de mejor manera la evolución de la zona tan conflictiva de la seguridad pública o ciudadana, lastrada por los reiterados cambios de rumbo en la concepción de las tareas de seguridad a cargo del Estado.

En términos de lo aquí señalado, la seguridad humana supera la idea de la seguridad pública o ciudadana, en la medida en que los indicadores del bienestar de los habitantes resultan, incluso, un tema que está más allá de la eficacia de las policías o la pulcritud de los procesos penales. Unos y otros elementos de la vieja concepción del Estado guardián se han desmoronado a la par que la idea de que el Estado es más fuerte cuando sus cuerpos de seguridad están mejor entrenados o cuentan con armamento más sofisticado; con esto también cae pronto la idea de que los jueces juzgan mejor si cuentan con equipo de videograbación o con juicios orales, abreviados y principio de oportunidad. Por ello, la seguridad humana se apunta como un argumento sólido y viable para atender la grave crisis de inseguridad que vivimos. Incluso, en el recorrido temporal de una década, desde que Felipe Calderón tomó la decisión de enfrentar el problema de la inseguridad con el auxilio del ejército, la evaluación no podría ser más frustrante: miles de víctimas en "daños colaterales", y los cárteles de la droga, con cambios mínimos de dirigentes y nomenclatura, siguen presentes en nuestra vida colectiva. La inseguridad es lamentablemente el sello de esta época y, con

20 "En definitiva, la seguridad humana se expresa en un niño que no muere, una enfermedad que no se difunde, un empleo que no se elimina, una tensión étnica que no explota en violencia, un disidente que no es silenciado. La seguridad humana no es una preocupación por las armas: es una preocupación por la vida y la dignidad humanas", 1994, Programa de las Naciones Unidas para el Desarrollo, p. 25, disponible en: http://hdr.undp. org/sites/default/files/hdr_1994_es_completo_nostats.pdf. A partir de esta referencia inicial, se han generado nuevos desarrollos que incluso plantean una mayor apertura al concepto aquí tratado. "Se puede afirmar, por lo tanto, que si la seguridad humana atañe a la seguridad de los individuos y de las comunidades, y comprende los derechos humanos y el desarrollo humano, la salvaguarda de la cultura se vuelve una parte indispensable e indivisible de la seguridad humana", Morales Sánchez, Noa, "Seguridad humana y ataques intencionales a la cultura: hacia una perspectiva amplia de las inseguridades humanas", Revista de Relaciones Internacionales de la UNAM, México, núm. 118, enero-abril de 2014, p. 68. 
ello, el bienestar y cualquier otra aspiración elemental de los habitantes es simplemente inaccesible.

Ahora bien, derivado de la actuación irregular de las policías y el ejército, y toda vez que la seguridad humana es un concepto que poco se conoce, difícil es hacer la conexión epistemológica con las consecuencias que esto acarrea y los mejores escenarios para el abordaje de lo que se ha denominado "resiliencia comunitaria". En cuanto a este tópico, es claro que las agresiones a los particulares, derivadas de la actuación de las policías y el ejército, traen aparejadas varias consecuencias en las víctimas y sus familiares. De esto casi nada se ha dicho, porque la concepción y la ruta de nuestro derecho penal llegó a su culmen pensando que el Estado tiene enemigos ${ }^{21} \mathrm{y}$ hay que eliminarlos. Desde entonces hasta ahora, las víctimas y ofendidos siguen olvidados, a pesar de los grandes esfuerzos que la sociedad civil ha realizado, para llamar la atención del gobierno en asuntos esenciales como la reparación del daño y la rehabilitación de los derechos humanos de víctimas y ofendidos. La idea de la resiliencia como vía de acceso a mecanismos de rehabilitación es otra cuestión neonata, cuyo mayor impulso ha venido de la sociedad civil. Esto es, sin duda, lamentable y reprochable, pues han tenido que suceder eventos tan graves (algunos más conocidos que otros) como la desaparición forzada, la tortura, el homicidio ex profeso de periodistas ${ }^{22}$ o el encarcelamiento de políticos opositores, para asumir que el funcionamiento del Estado no está en su mejor momento.

Con la visión hasta aquí desarrollada, la inocultable ruptura entre la visión normativa y la realidad resalta la necesidad de estudiar y atender más allá de la reparación del daño y la resiliencia individual, para proyectar el quid del Estado hasta la resiliencia comunitaria que representa otro de los grandes esfuerzos de la sociedad civil organizada, para abonar desde la cooperación colectiva al saneamiento de las heridas que las secuelas de esta

21 En este sentido se expresa la corriente del derecho penal que ha llegado al extremo de afirmar que en el Estado hay ciudadanos y enemigos; de este modo, la observancia del respeto a los derechos fundamentales y sus garantías introduce una peligrosa distinción con referencia a quienes infrinjen la norma y se sitúan, de inmediato, como enemigos del Estado. Véase la obra de Jakobs, Günther y Cancio Melia, Manuel, Derecho penal del enemigo, Navarra, Civitas, 2006.

22 Por si faltara una referencia más, baste con citar los asesinatos de Miroslava Breach (http://www.jornada.unam.mx/2017/03/24/politica/002n1pol) y de Javier Valdéz (http://www.jornada.unam.mx/2017/05/16/politica/002n1pol), ocurridos en menos de dos meses y que son muestra evidente de la fractura social, donde la libertad y la verdad parecen estar vedadas. 
guerra han dejado en las viudas y huérfanos de aquellos que por la ausencia de políticas públicas adecuadas han desaparecido.

\section{POLICÍA PARA LA POLIS}

En seguimiento a lo que aquí hemos planteado, las expresiones primigenias de un Estado constitucional se plasman en seguridad y bienestar; seguridad más allá de la añeja concepción de la policía, el armamento y la represión; bienestar, tangible en los mínimos vitales que ofrezcan a los habitantes alguna perspectiva de capilaridad social. En cuanto a lo primero, ¿por qué es tan difícil hacer que la policía cumpla con su tarea? Tal es la pregunta que se formulan los ciudadanos lastimados por la delincuencia. ¿Por qué hay delincuencia? Tal es la pregunta que todos nos hacemos a diario. Una y otra respuesta tienen su explicación más conspicua en las condiciones sociales, económicas e incluso de orden cultural de la sociedad actual. Para entender esto, para explicarlo, no hacen falta grandes luces ni talentos excepcionales; sí, en cambio, se requiere especialización y un sentido común altamente desarrollado, para establecer las líneas discursivas de los planes, programas y acciones que se deben realizar para atender esta problemática tan enquistada en el tejido social.

Necesitamos una policía para la ciudad; mejor dicho, requerimos una policía para los ciudadanos. Una policía que, siendo poder del Estado, deba atender los valores superiores de la vida humana social y, en correspondencia con ello, la policía - cuyos miembros son también parte del conjunto social - necesita del apoyo de ciudadanos responsables, maduros, respetuosos. Es obligación constitucional del Estado otorgar protección a los habitantes; es obligación de los ciudadanos cultivar el respeto a la autoridad. Lamentablemente, estos dos grandes soportes de la vida social han colapsado por la influencia del dinero, la corrupción y las prácticas ilegales que han configurado una subcultura (incultura) de la violación a la ley, la falta de respeto a la autoridad, el enriquecimiento ilícito y las vías más cómodas para la obtención de satisfactores, sin el riesgo de ser sancionado.

Toda esta gravísima problemática converge en la práctica social del desacato a la ley, la mofa de la autoridad, la transgresión sin consecuencias, y todo ello permea en la sociedad y trasciende hasta los más jóvenes. La gravedad de todo esto nos ha llevado hasta el peligroso extremo de autorizar 
la prisión preventiva para menores de edad ${ }^{23}$ involucrados en la comisión de delitos graves, lo que lejos de dar claridad a la resolución de estos asuntos tan punzantes para la sociedad, ha servido solamente para mostrar con toda su crudeza la realidad de un Estado ausente que no ha generado políticas públicas para la recreación, la salud plena, el empleo, el crecimiento y la inclusión social. ${ }^{24}$

Con todo esto, lo que de manera coloquial y vergonzante podemos llamar desde ahora cárteles de niños, es una oleada de seres humanos dejados a su suerte por el Estado fallido, incapaz y desinteresado en formarlos y hacer de ellos ciudadanos de bien. Los adolescentes son, en este caso, útiles para el crimen organizado y manifestación indubitable de la incapacidad de quienes gobiernan para combatir a los delincuentes adultos que son quienes usan y reclutan a los menores de edad; desde luego, el Estado debe erradicar el crimen de los adultos por las vías adecuadas, focalizando el ejercicio de la potestas en quienes generan el fenómeno delictivo y no en quienes les sirven para burlar a la autoridad, mediante la consabida fórmula de la inimputabilidad.

Así las cosas, un tópico de gran relevancia en este ejercicio teórico está constituido por la necesidad de contar con un modelo policial ${ }^{25}$ acorde con esta nueva perspectiva del derecho humano a la seguridad humana. Es incontestable que no cualquier tipo de policía comulga con el tipo de Estado que hemos planteado a lo largo de este documento. La premisa construida desde la necesidad de superar el Estado de derecho cobijado por el principio

23 "El pleno de la Suprema Corte de Justicia de la Nación (SCJN) avaló la prisión preventiva para adolescentes (de 14 a 18 años de edad), acusados de delitos graves hasta por cinco meses, en tanto se dicta sentencia", disponible en: http://www.jornada.unam. mx/ultimas/2017/05/08/scjn-avala-prision-preventiva-para-adolescentes.

24 La inclusión social tiende a configurarse como un derecho humano de última generación; de cara a la persistente actitud de indolencia y desinterés del gobierno hacia los problemas sociales de mayor calado, la inclusión social pretende encontrar las opciones de mayor viabilidad para abatir la marginación y la miseria que frustran la vida de más de la mitad de la población de México.

25 El concepto de policía educadora puede ser una opción teórica en esta reconstrucción que es urgente para México. "La fonction de policier-éducateur emerge au confluent de politiques policiéres nationales et d'un agend public transnational qui incorpore progressivement des enjeux de prévention des déviances sous forme de plans et de programmes d'action en particulier en direction de la jeunesse"; Wuilleumier, Anne, "La policier-éducateur et l'effectivité du droit. Exploration comparée des répertoires policiers de pédagogie du droit en France et au Canada", Droit et Societé, Revue Internationale de Theorie du Droit et de Sociologie Juridique, núm. 97, 2017, p. 525. 
de legalidad y sus limitaciones inmanentes, nos arrojó desde un principio a la necesidad epistemológica de comprender y estudiar la seguridad pública en su más conspicuo desarrollo científico, abrigado desde los umbrales delineados por la ONU.

A más del fracaso de las políticas públicas adoptadas desde la visión represiva del Estado, la deconstrucción del concepto de "seguridad pública" y sus matices delineados desde la policía impreparada, los militares abusivos, los políticos corruptos y la connivencia cuasi-institucional, nos condujo hasta la necesidad de armar un constructo científico sobre el modelo policial más acorde con este nuevo diseño constitucional del Estado y de sus políticas públicas en seguridad pública y justicia penal.

De acuerdo con lo hasta aquí tratado, es inconcuso que el trazado teórico del Estado constitucional desde sus primeros atisbos democráticos y de estricto apego a derecho, debe conectarse con los otros argumentos teóricos que - como la estructura y naturaleza de la policía — son infaltables en el nuevo modelo de Estado constitucional vinculado a la necesidad de que sus políticas públicas estén debidamente diseñadas y resulten congruentes con el respeto inexcusable de los derechos de los habitantes.

En este contexto, el abuso de poder, la corrupción de las policías, los excesos del ejército, las complicidades de servidores públicos y las relaciones con los delincuentes, la impunidad y todos los lastres que han marcado la actuación del Estado en los dos campos multicitados de la seguridad y la justicia, resultan más que ofensivos e inaceptables para el Estado constitucional que justamente está soportado sobre la garantía plena de los derechos humanos y el estricto control del poder. ${ }^{26}$

De la mano con esta candente cuestión, todavía ni siquiera visualizada desde la óptica de un paradigma debidamente pensado que nos pueda dar luz más allá de la propuesta del mando único, ${ }^{27}$ la actuación de agentes del

26 Para ilustrar el estado de la cuestión en este campo, puede verse, Contreras López, Rebeca Elizabeth, "La mirada internacional: informes para México sobre DDHH, impunidad e inseguridad", Letras Jurídicas, México, año 17, núm. 34, julio-diciembre de 2016 (33-48).

27 En este tópico concreto, la burda aproximación a la idea del "mando único policial" en las entidades federativas - merced a la fragilidad y porosidad de las policías municipales, impreparadas y fácilmente corrompibles - ha sido una desafortunada ocurrencia que no ha medido las consecuencias de dar un poder de tal magnitud a los gobernadores - también frágiles y permeables a la corrupción- La discusión ni siquiera ha reparado en algo elemental: un mando único requiere una policía única; única y uniforme en atribuciones y competencias; no como ahora, que unos policías "dan vialidad" y otros sí pueden "dar se- 
Ministerio Público y jueces es otro asunto que requiere atención urgente y, evidentemente, una reforma que transforme la desgastada visión del culpable, que resulta deleznable en la violación de un principio universal de los derechos humanos, que es la presunción de inocencia. Los vicios cognitivos de los que investigan y de quienes juzgan son otro gravísimo problema de esta maquinaria enmohecida, que más allá de una reparación mínima para ajustar sus piezas y aceitarlas, requiere un reemplazo de esa maquinariasistema y un cambio y adiestramiento puntual de sus operarios, para que sean capaces de investigar y juzgar científicamente.

En otro rubro también destacado, es incontestable que la actuación de los órganos encargados de procurar e impartir justicia adolece de diversos vicios en sus respectivos campos; unos, con la manera poco profesional de tratar las cuestiones inherentes a la investigación y jalonados por los prejuicios que las muchas horas de experiencia práctica les ha dejado; los otros, con carencias manifiestas en el campo de la argumentación y con la presencia, por lo general infaltable, del vicio de confirmación. Juntos, estos dos importantes momentos de la tarea estatal de hacer justicia nos muestran un contexto que, desde luego, no es el más halagüeño para quienes son vinculados a proceso y luego sentenciados; lo mismo podemos decir de quienes esperan que los delitos sean castigados y que la reparación del daño sea un asunto visible para víctimas y ofendidos. En este último campo, poco se puede decir de la reparación no pecuniaria del daño ${ }^{28}$ que, siendo un tema esencial en esta materia, resulta casi desconocido para quienes piden justicia y, en algunos inaceptables casos, también para los servidores públicos que deben procurarla y ponerla al alcance de la mano de quienes han sido agraviados.

Con todos los campos que aquí se han descrito, la agenda para el Estado constitucional está repleta de compromisos y retos; de grandes tareas no colmadas y de muchos programas que deben ser instrumentados con la adecuada visión temporal que permita a sus destinatarios vivenciar los derechos humanos. ${ }^{29}$

guridad", o como en el cuestionable ensayo que en el Estado de México — durante algunos meses - reservó a las mujeres la capacidad para infraccionar a los automovilistas, con el pueril argumento de que los hombres son más corruptos. Véase http://circuito.mx/component/k2/item/25-nuevo-reglamento-de-transito-del-estado-de-mexico.html.

28 León Bastos, Carolina, "Las reparaciones no pecuniarias en el sistema interamericano de derechos humanos", Juris Tantum, México, núm. 25, diciembre de 2014.

29 Para una mejor comprensión de esto, el lector puede consultar Uribe Arzate, Enrique, "Una aproximación epistemológica a los derechos humanos desde la dimensión 


\section{LA DEMOCRACIA VIVENCIAL}

En este orden de ideas, la concepción del Estado constitucional asentada en la procura de bienestar de los habitantes tiene que basarse, a fortiori, en las posibilidades (y limitaciones, si así se quiere ver) de la democracia. De entre las definiciones y orientaciones teóricas que van moldeando el nuevo perfil del Estado, la revisión misma de la democracia y su tipología nos lleva al encuentro de nuevas expresiones de este modo de ser de las sociedades. Los argumentos a favor de una democracia deliberativa son el acercamiento inicial a otra de las características inmanentes del Estado constitucional — capaz de prodigar seguridad humana y justicia a sus habitantes-.

De este modo, la vivencia de un modelo democrático que deposita en los ciudadanos las capacidades de decisión abre la oportunidad a nuevos desarrollos de lo público. ${ }^{30}$ En la misma línea de pensamiento, la apertura democrática conlleva una gran carga de responsabilidad ciudadana ${ }^{31} \mathrm{y}$, por ello, al asumir que la vida democrática es un asunto cotidiano, la participación y el involucramiento en los temas comunes, como la inseguridad y la injusticia, reclama — por qué no decirlo — otro tipo de ciudadanos, distintos a quienes asumen que los problemas debe resolverlos "el Estado" - para decirlo con mayor concreción, quienes coyunturalmente ocupan los espacios de decisión política-.

Así las cosas, el constructo teórico que se ha delineado a lo largo de estas páginas inicia con la fe puesta en el sistema democrático del Estado que debemos asumir como el único espacio para la vida social, "forma de vida

vivencial pragmática”, Boletín Mexicano de Derecho Comparado, México, vol. 44, núm. 132, 2011.

30 Lo público, entendido aquí como sinónimo de lo estatal, tiene un anclaje sumamente interesante en la idea de "el orden público" — punto de partida, capacidad y límite para el ejercicio de las libertades_- "El orden público debe ser considerado como un mecanismo jurídico al servicio de la garantía de los derechos y libertades, de su tutela y protección, ésta sería su verdadera esencia funcional, y su justificación, por ello, no puede encontrarse fuera del Derecho positivo, pues ello atentaría contra su propia esencia"; Bartolomé Cenzano, José Carlos de, El orden público como límite al ejercicio de los derechos y libertades, Madrid, Centro de Estudios Políticos y Constitucionales, 2002, p. 151.

31 Sin duda, la carga de responsabilidad a que nos referimos sólo puede ser ubicada en ciudadanos de tiempo completo. Véase, Meyer, Lorenzo, El Estado en busca del ciudadano, un ensayo sobre el proceso político mexicano contemporáneo, México, Océano, 2005. 
humano-social, vida en forma y forma que nace de la vida", ${ }^{32}$ que puede servir de escenario y asiento a la vida de los hombres. "La democracia es una apertura de crédito al homo sapiens, a un animal suficientemente inteligente para saber crear y gestionar por sí mismo una ciudad buena. Pero si el homo sapiens está en peligro, la democracia está en peligro". ${ }^{33} \mathrm{La}$ democracia se vuelve así herramienta y fin, y, con ella, las posibilidades de actuación del Estado se potencian hacia la gobernanza, posibilidad y meta común de los habitantes - gobernantes y gobernados-.

Pero es cierto que un tipo de democracia como la aquí apuntada necesita afianzar algunos principios que todavía son frágiles, como la igualdad entre los habitantes que no admite categorías ni atenuaciones. Mientras esto no se vuelva cosa de todos los días, nuestra sociedad seguirá oscilando entre sus múltiples problemas y, en el caso concreto que nos ocupa, la seguridad humana se volverá poco menos que una frívola manera de entender la entrega de despensas para atenuar la miseria y el hambre de un amplio sector de los habitantes.

En congruencia con esto, ser iguales y comprendernos así implica la puesta en marcha de una amplia e intensa actividad estatal para el diseño de un modelo de Estado que en gran medida se aproxima al Estado social, necesariamente democrático y constitucional —el único proclive a la nivelación social, al aminoramiento de las desigualdades- . De este modo, el Estado constitucional, democrático y social, se sitúa frente a nosotros como el paradigma teórico pertinente y como la concreción política y vivencial para que la seguridad humana y la justicia resulten posibles en este agitado mundo de la improvisación y de los ensayos inacabados.

Esto que resulta visible desde el promontorio del observador social, lamentablemente es vivencia y padecimiento cotidiano para los habitantes en general. Por esta razón, el armado de un constructo científico pertinente ha requerido el eslabonamiento de múltiples asuntos que aun pareciendo distintos, guardan entre sí una poderosa conexión. Si la democracia deliberativa se anuncia como conditio sine qua non para atender estos problemas, es innegable que la maduración social debe estar a punto para volcar sobre las acciones (y las omisiones) del gobierno, la exigencia de rendición de cuentas y la transparencia en la toma de decisiones; asimismo, en la manera de concebir proyectos y ponerlos en marcha.

\footnotetext{
32 Heller, op. cit., p. 69.

33 Sartori, Giovanni, ¿Qué es la democracia?, México, Taurus, 2007, p. 440.
} 
En esta nueva ruta que afina la concepción y praxis de la democracia, no olvidemos que los derechos humanos cuestan; no pasemos por alto que el cambio de rumbo que se necesita en la forma de entender y abordar los problemas de inseguridad e injusticia debe ir acompañado del respaldo económico suficiente para hacer posible esta ruptura con el obsoleto modelo de seguridad pública o ciudadana y la anquilosada manera de investigación policial que presupone escenarios (y hasta fabrica responsables) en lugar de investigar científicamente el iter criminis.

En la parte final de este armazón teórico, así como hemos insistido en que los derechos humanos se vuelvan vivencia cotidiana, la democracia no tiene otra ruta para su realización eficaz en la vida de todos los días. Nos parece que el concepto de democracia vivencial ${ }^{34}$ puede auxiliarnos a comprender de mejor manera qué tipo de articulación requerimos como sociedad organizada de rostro humano. Esta nueva tipología de la democracia se puede comprender como el quehacer humano-social, pertinente para alcanzar el pleno desarrollo de las capacidades humanas en la vida comunitaria. Vivir en democracia, afirmar el ejercicio constitucional, responsable y humano del poder, entender la función policial como algo cercano a todos, ver la seguridad humana como el patrimonio y la riqueza consustanciales a la sociedad, serán, a partir de ahora, los elementos esenciales para configurar las tareas de seguridad pública y justicia penal, como la expresión invariable de la mesura, la certidumbre y la protección que todos los habitantes esperamos del poder público.

\section{PRÓXIMAS TAREAS}

Ante una complejidad tan abrumadora como la que apenas hemos delineado a lo largo de estas páginas, el esbozo de lo que está por venir debe enfocarse en el diseño de políticas públicas para atender, desarrollar y potenciar la seguridad humana al seno del Estado constitucional; al respecto, resulta

34 Este concepto puede verse en trabajos de corte psicológico y social; vgr., Restrepo R, Luis Carlos, "Democracia vivencial y cultural de la convivencia", Nómadas (col), Bogotá, Colombia, núm. 2, marzo de 1995; otro texto es de García Suárez, Carlos Iván y González Valencia, Ana Milena, "Democracia vivencial en la escuela: la construcción de la equidad y la inclusión en el aula”, Nómadas (col), Bogotá, Colombia, núm. 12, 2000. Por nuestra parte, creemos que en el plano jurídico-político, la importancia de este concepto crece exponencialmente. 
vital que el presupuesto destinado a tales fines quede exento del debate ocioso y la negociación reprobable de políticos y facciones partidistas, tan acostumbrados a medrar con estas materias, porque la vida, el hambre, la seguridad y la justicia de nuestros iguales no deben mecerse al vaivén de los calendarios electorales ni del oportunismo deleznable de quienes son capaces de celebrar alianzas hasta con sus opositores ideológicos.

Por eso, la política necesita un constructo teórico superior. Partidos políticos y sistemas electorales no serán más en el corto plazo, si sus protagonistas no dejan a un lado la ignara creencia de que la democracia es sólo proceso, tiempo y definición de nuevos gobernantes y no forma de vida cotidiana, asentada en el reto diario de mejorar las difíciles condiciones de vida — a veces infrahumana de muchos habitantes-, particularmente de los millones de miserables que hay en cualquier sitio del orbe y, desde luego, de México.

De esta manera, el Estado constitucional, democrático y social se anuncia como la primera e irremplazable condición para hacer posible el acercamiento de los humanos a un contexto donde la "seguridad humana" reemplaza dádivas y despensas por programas de inmanente contenido social. Ahora bien, los votos también deben ser para el veto; por eso, el escenario que aquí esbozamos pugna por una democracia de los libres e iguales, de los responsables, de los ciudadanos informados y exigentes, capacitados para retirar su confianza a los ineptos y a los corruptos.

Para superar la aporía que significa el Estado constitucional de recio contenido, imbatible, y las carencias sociales que sin duda lo niegan y aniquilan, el Estado y su gobierno deben refrendar a cada momento su carácter social, solidario y humano, a través de políticas públicas que materialicen y hagan realidad el compromiso del poder público con la constante mejora de las condiciones de vida de los habitantes. En este modelo democrático, la seguridad y la justicia son los dos grandes pilares que sostienen al Estado, son la esencia misma de la organización política-social de los seres humanos. Pero nada sirve si los elevados principios que dan asiento al edificio social no están al alcance de la mano de los habitantes; para ello se requieren otros elementos, como los que ya hemos invocado a lo largo de este trabajo: justicia (particularmente la penal) pronta y expedita, con jueces sensatos, probos y capaces; escenarios óptimos para la atención de víctimas y ofendidos; planes y programas para la eficaz resiliencia comunitaria; una policía científica (con mando único o con un único mando), preventiva, correctiva, ministerial, con elevada preparación para entender 
que la brutalidad y la tortura van acompañadas de procesos de responsabilidad penal. Sobre todo, se requiere un sistema jurídico-político que prevea todo esto: los pormenores de la preparación de policías, agentes del Ministerio Público, jueces y defensores; un sistema de responsabilidades para poner coto a los desmanes y abusos de los funcionarios (cualquiera que sea su tarea o categoría); programas para la atención y rehabilitación de víctimas y ofendidos; y en los latidos cotidianos del Estado, políticas públicas de largo aliento, fuera del alcance de los partidos políticos y de sus acomodaticios protagonistas; en suma, se necesita un nuevo modelo de Estado constitucional, social, humano y solidario.

Tenemos confianza en que los años que todavía le restan a este problemático siglo XXI le permitirán a la humanidad revolucionar la concepción del Estado, asiento de nuestros afanes y luchas, escenario insuperable de nuestra zozobra, pero también entidad de manifiesta capacidad para hacer de los hombres algo cada día más humano. Con lo anterior, la hoja de ruta en la búsqueda de respuestas racionales y pertinentes debe aprovechar - paradójicamente - este contexto, para realizar una reflexión de corte filosófico-jurídico que retome el debate en torno a la naturaleza del Estado y del derecho, hoy empantanados en las indefiniciones y la improvisación, cuando no, hasta en las ocurrencias.

Este ejercicio es sumamente pertinente, porque nos permite poner de relieve y apreciar en toda su magnitud una de las razones más importantes por las que el Estado debe evolucionar hacia su dimensión constitucional, particularmente en el "debido proceso penal", que es una de sus facetas más visibles y próximas, donde los habitantes resienten la crisis a que nos hemos venido refiriendo. El ejercicio del poder público, la puesta en marcha de políticas públicas debidamente estudiadas y diseñadas, las adecuaciones urgentes al sistema penal, la maduración de la función policial y la rehabilitación de los derechos de víctimas y ofendidos, son asuntos que exigen atención inmediata.

Como lo hemos indicado, la quiebra del modelo de Estado que encumbró la división de poderes y la legalidad ha dado la pauta para la revisión de los campos de la justicia y seguridad humana. El fracaso que se ha evidenciado en cualquier parte del orbe, donde la summa potestas apela al uso legítimo - y a veces brutal y desmedido — de la fuerza, a la opresión y la improvisación, ha generado un ambiente de desconcierto y desconfianza. No bastan las reglas jurídicas para la convivencia; es necesario que esas reglas funcionen adecuadamente, sobre todo de manera clara y equitativa, pues 
como dice Bobbio: "Con el pacto de no agresión recíproca los individuos abandonan el estado de naturaleza; con el pacto de obediencia a las reglas establecidas de común acuerdo constituyen una sociedad civil. Pero sólo instituyendo un poder común dan vida a un Estado".35

Si el sistema jurídico que propició el desarrollo de lo público ha colapsado, no vemos por qué razones no superamos la necedad de continuar con la infortunada repetición de mecanismos y tareas que ya demostraron su ineficacia; entre los más sensibles, la infausta guerra contra el narcotráfico, la proliferación de armamento entre civiles, la dimensión inhumana del sistema penitenciario (entiéndase: la nula rehabilitación de los delincuentes), la atención apenas tangencial a la pobreza y la mirada esquiva hacia los más miserables (caldo de cultivo de cualquier otro problema social).

Si el Estado es un medio de control social — y eso debe seguir siendo-, una discusión teórica de mayores alcances debe considerar la expresión endémica de la violencia estatal que al actualizar sus mecanismos de operación (policiales, jurídicos, económicos) no hace sino alentar la violencia social, la inestabilidad y la ingobernabilidad que a todos nos vuelve inciviles. Es inexcusable la necesidad de un debate en torno a la configuración y las pautas a seguir del Estado para los años venideros. ${ }^{36}$

Ahora bien, otra cuestión esencial en esta proyección teórica sobre el quid del Estado es la necesaria aquiescencia entre quienes mandan y quienes obedecen, que aumenta las posibilidades reales de vivir en un escenario idóneo para la vida humano-social en el marco de lo estatal. Lo cierto es que esa condición de cercanía y mutua aceptación no puede generarse sin un mínimo de claridad en las reglas de operación. Ante la poca atención —y a veces nula respuesta - del gobierno a los reclamos y solicitudes de los gobernados, la desconfianza hacia el poder público se desencadena de inmediato. En este orden de ideas, la potestad sin auctoritas de quienes gobiernan se ha convertido, para nuestra mala fortuna, en un lugar común en casi cualquier ámbito de la vida pública. El abuso de poder, tan enquistado en nuestras sociedades, está carcomiendo la esencia de lo estatal y, por eso, no debe causarnos asombro el fracaso del Estado liberal, formalista y legal que poco o nada atiende valores superiores, principios y reglas constitucionales, para que los derechos humanos se

\footnotetext{
35 Bobbio, Norberto, Teoría general de la política, Madrid, Trotta, 2003, p. 416.

36 Véase, Gargarella, Roberto (coord.), La Constitución en 2020, 48 propuestas para una sociedad igualitaria, Argentina, Siglo XXI Editores, 2011.
} 
vuelvan vivenciales, y el ejercicio y control del poder público un tema cotidiano en la democracia vivencial.

$\mathrm{Y}$ es que en el marco de un sistema jurídico genuino — necesariamente constitucional-, debe haber estándares mínimos de confianza y cercanía, e incluso de lealtad, ${ }^{37}$ como lo sugiere la articulación cotidiana entre gobernantes y gobernados. Ya vimos que para esto es necesario que el aparato gubernamental brinde respuestas claras, transparentes, así como acciones concretas y efectivas que constaten la empatía y proximidad con los gobernados, pero, sobre todo, debe confirmar con su actuación el respeto invariable de la dignidad humana en cualquiera y en todas sus manifestaciones, id est, lo mismo para la operación del sistema de justicia que para el ejercicio de atribuciones para mantener el orden; lo mismo en tareas jurisdiccionales que en el uso de los programas para combatir la miseria; es claro que un gobierno de este cariz está muy lejos de nosotros, y resulta inobjetable que la condición inmanente para su puesta en operación es el modelo de Estado constitucional, solidario, social, humanista, garante indiscutible de los derechos esenciales de las personas.

Con lo antes apuntado, queda claro que la concepción científica del Estado constitucional, su diseño jurídico e institucional, y la adopción y puesta en marcha de políticas públicas, no pueden desconectarse de la realidad que circunda y envuelve a ese Estado-tipo. Hasta hoy, ha sido un error tremendo creer que la cosa pública camina por sí misma, ajena a las condiciones sociales; al segmentar de este modo la comprensión de lo estatal, el artificio que ello implica y la consecuente simulación de resultados por su inadecuada operación, se han estrellado contra la realidad que invariablemente pone a cada cosa en su sitio. Hoy, la concepción anquilosada de la cosa pública y la fragmentación de esfuerzos en el intento de atender múltiples necesidades ha cedido paso franco a la improvisación y, con ello, a magros resultados que se palpan de inmediato en el tejido social.

Así pues, el Estado constitucional debe fortalecer su diseño y atribuciones desde la garantía de los derechos humanos. Este es el único Estado

37 "Identificar lealtad con obediencia ciega es desvirtuar la lealtad. La lealtad crítica también es lealtad y no tiene esta connotación negativa desde el punto de vista de la filosofía liberal. Por ejemplo, un desobediente civil podría ser considerado una persona leal a la Constitución en su conjunto porque reclama que alguna ley es contraria a una correcta interpretación de la Constitución y que, además, requiere seguir siendo legal a la Constitución, porque su correcto entendimiento lo requiere"; Calsamiglia, Albert, Cuestiones de lealtad, límites del liberalismo, corrupción, nacionalismo y multiculturalismo, Barcelona, Paidós, 2000, p. 56. 
que tiene posibilidades de ser; de lo contrario, carente de legitimidad y de los asideros adecuados en la zona basal de la sociedad, estará condenado a ceder el paso a otras formas de organización jurídica, política, social y económica, más allá de sus fronteras y más allá del espectro tradicional de su poder y autoridad; para el Estado poroso, desvinculado de su justificación primaria, prístina, que es la búsqueda del bienestar de sus miembros, el abuso de poder y las estructuras corrompidas ${ }^{38}$ son la amenaza mayor y pueden marcar el momento crucial de su paulatina o pronta desaparición.

\section{FUENTES DE CONSULTA}

\section{Bibliográficas}

Aguilar Villanueva, Luis F., El estudio de las políticas públicas, México, Miguel Ángel Porrúa, 2007.

Aguilar Villanueva, Luis F., La implementación de las políticas públicas, México, Miguel Ángel Porrúa, 2007.

ARAGÓN REYES, Manuel, "Dos problemas falsos y uno verdadero: «neoconstitucionalismo», "garantismo» y aplicación judicial de la Constitución", Cuestiones Constitucionales, Revista Mexicana de Derecho Constitucional, México, núm. 29, julio-diciembre de 2013.

38 Al respecto, es elocuente esta referencia sobre lo que sucedió en Roma: "Cabría afirmar, en definitiva, a la vista de los abundantes testimonios contenidos en las fuentes romanas, que la conformación de la policía urbana, la policía exterior, la actividad de los delatores, el servicio de espionaje, la guardia pretoriana, o el servicio palatino de seguridad se presentan, en suma, como un mosaico variopinto de investigación, al propio tiempo de represión, corrupción, transgresión de facultades ejercitadas, abuso de poder en el ejercicio de las labores legítimamente atribuidas y al propio tiempo de seguridad jurídica, orden interno, control del aparato del estado, vigilancia de los enemigos exteriores que, paradojas y enseñanzas de la historia, nos acercan al panorama que es objeto de reiterado [sic] denuncia en los medios de comunicación de nuestro tiempo y en los tribunales de justicia, en relación con espionaje telefónico, programas de escuchas a particulares sin autorización judicial, espionaje en internet, venta de datos de información confidencial, corrupción de agentes de espionaje, etc.”; Fernández de Buján, Antonio, "Conformación de las nociones de seguridad ciudadana, orden interno, seguridad exterior y policía política. De los vigiles a los agentes in rebus", Studia et Documenta Historiae et Iuris, Cittá del Vaticano, LXXXII, 2016. El parecido de la sociedad de aquel entonces con la nuestra es preocupante. 
Bartolomé Cenzano, José Carlos de, El orden público como límite al ejercicio de los derechos y libertades, Madrid, Centro de Estudios Políticos y Constitucionales, 2002.

Bobbio, Norberto, Teoría general de la política, Madrid, Trotta, 2003.

Calsamiglia, Albert, Cuestiones de lealtad, límites del liberalismo, corrupción, nacionalismo y multiculturalismo, Barcelona, Paidós, 2000.

CONTRERAS LÓPEZ, Rebeca Elizabeth, "La mirada internacional: informes para México sobre DDHH, impunidad e inseguridad", Letras Jurídicas, México, año 17, núm. 34, julio-diciembre de 2016.

Cordera CAmpos, Rolando y Provencio Durazo, Enrique (coords.), Informe del desarrollo en México 2015, México, UNAM, 2016.

Cordera CAmpos, Rolando (coord.), Percepciones, pobreza, desigualdad. Encuesta nacional de pobreza, México, UNAM, 2015.

CHOMsky, Noam, La quinta libertad, Barcelona, Crítica, 1988.

FERNÁNDEZ DE BUJÁN, Antonio, “Conformación de las nociones de seguridad ciudadana, orden interno, seguridad exterior y policía política. De los vigiles a los agentes in rebus", Studia et Documenta Historiae et Iuris, Cittá del Vaticano, LXXXII, 2016.

FLORES, María Victoria, "La globalización como fenómeno político, económico y social”, Orbis. Revista Científica Ciencias Humanas, Venezuela, vol. 12, núm. 34, 2016, disponible en: http://www.redalyc.org/ articulo.oa? id=70946593002 (consultado el 21 de junio de 2018).

GArcía SuÁrez, Carlos Iván y GonZÁlez VAlencia, Ana Milena, “Democracia vivencial en la escuela: la construcción de la equidad y la inclusión en el aula", Nómadas (col), Colombia, Bogotá, núm. 12, 2000.

GARGARElla, Roberto (coord.), La Constitución en 2020, 48 propuestas para una sociedad igualitaria, Argentina, Siglo XXI Editores, 2011.

HELD, David, La democracia y el orden global, del Estado moderno al gobierno cosmopolita, Barcelona, Paidós, 1997.

Heller, Hermann, Teoría del Estado, México, FCE, 2000.

IANNI, Octavio, La sociedad global, México, Siglo XXI Editores, 2007.

JAKOBS, Günther y CANCIO MELIA, Manuel, Derecho penal del enemigo, Navarra, Civitas, 2006.

KAHN, Paul W., "Una nueva perspectiva para el constitucionalismo comparado: el análisis cultural del estado de derecho occidental", Revista de Derecho, Valdivia, vol. XXIX, núm. 1, junio de 2016. 
LEÓN BASTOS, Carolina, "Las reparaciones no pecuniarias en el sistema interamericano de derechos humanos", Juris Tantum, México, núm. 25, diciembre de 2014.

MEYER, Lorenzo, El Estado en busca del ciudadano, un ensayo sobre el proceso político mexicano contemporáneo, México, Océano, 2005.

MorAles SÁNCHEZ, Noa, "Seguridad humana y ataques intencionales a la cultura: hacia una perspectiva amplia de las inseguridades humanas", Revista de Relaciones Internacionales de la UNAM, México, núm. 118, enero-abril de 2014.

RESTREPO R, Luis Carlos, "Democracia vivencial y cultural de la convivencia”, Nómadas (col), Bogotá, Colombia, núm. 2, marzo de 1995.

SARTORI, Giovanni, ¿Qué es la democracia?, México, Taurus, 2007.

STAVENHAGEN, Rodolfo, "Un mundo en el que caben muchos mundos: el reto de la globalización”, en GUTIÉRREZ MARTínEZ, Daniel y BALSLEV Clausen, Helene (coords.), Revisitar la etnicidad, miradas cruzadas en torno a la diversidad, México, El Colegio de Sonora-El Colegio Mexiquense-Siglo XXI Editores, 2008.

URIBE ARZATE, Enrique, "Una aproximación epistemológica a los derechos humanos desde la dimensión vivencial pragmática", Boletín Mexicano de Derecho Comparado, México, vol. 44, núm. 132, 2011.

VAladÉS, Diego, Problemas constitucionales del Estado de derecho, Buenos Aires, Astrea, 2004.

Wuilleumier, Anne, "La policier-éducateur et l'effectivité du droit. Exploration comparée des répertoires policiers de pédagogie du droit en France et au Canada", Droit et Societé, Revue Internationale de Theorie du Droit et de Sociologie Juridique, núm. 97, 2017.

\section{Electrónicas}

1994, Programa de las Naciones Unidas para el Desarrollo, disponible en: http://hdr.undp.org/sites/default/files/hdr_1994_es_completo_nos tats.pdf.

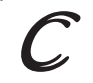

Fecha de recepción: 14 de septiembre de 2017.

Fecha de aceptación: 10 de diciembre de 2018. 